\title{
SLC41A1 and TRPM7 in magnesium homeostasis and genetic risk for Parkinson's disease
}

\author{
Morgan Sturgeon', Perry $\mathrm{Wu}^{2}$, and Robert Cornell ${ }^{1,2^{*}}$ \\ 'Molecular and Cell Biology Graduate Program, University of lowa, lowa City, lowa \\ ${ }^{2}$ Department of Anatomy and Cell Biology, University of lowa, lowa City, lowa
}

\section{Article Info}

\section{Article Notes}

Received: November 29, 2016

Accepted: December 30, 2016

\section{*Correspondence:}

Dr. Robert A. Cornell, Professor, Department of Anatomy and Cell Biology, 1-400D Bowen Science Building

Carver College of Medicine, University of lowa, lowa City, lowa 52242, USA, Telephone: (319) 335-8908, FAX: (319) 335-7198 Email: robert-cornell@uiowa.edu

(c) 2016 Cornell $R$. This article is distributed under the terms of the Creative Commons Attribution 4.0 International License

\section{ABSTRACT}

Parkinson's disease (PD) is a neurodegenerative disorder of the central nervous system with a clinically heterogeneous presentation that includes progressive loss of dopaminergic (DA) neurons in the substantia nigra. A minority of PD cases are familial and are caused by mutations in single genes. Most cases, however, are idiopathic PD, a complex multifactorial disorder with environmental and genetic contributors to etiology. Here, we first briefly summarize published evidence that among environmental contributors is dietary deficiency of magnesium. We then review genetic data suggesting that mutations in genes encoding two proteins contributing to cellular magnesium homeostasis confer risk for PD or other Parkinsonian conditions. First, the gene encoding magnesium transporter SLC41A1 is, among others, a candidate for the causative gene in the PARK16 locus where variation is associated with risk for idiopathic Parkinsonian disease. Studies of the function of SLC41A1 in animal models are needed to test whether this protein has a role in maintenance of dopaminergic neurons. Second, in a small study, a hypomorphic variant of TRPM7, a magnesium-permeable channel, was over-represented in cases of amyotrophic lateral sclerosis/ Parkinson dementia complex versus controls from the same ethnic group. Although this association was not detected in a second study, in zebrafish Trpm7 is necessary for terminal differentiation and reduction of toxin-sensitivity in dopaminergic neurons. Overall, epidemiological results support the possibility that mutations in genes relevant to magnesium homeostasis would alter PD risk, but deeper genetic analyses of PD patients are necessary to confirm whether SLC41A1 and TRPM7 are among such genes.

\section{Abbreviations}

Parkinson's Disease (PD), cerebrospinal fluid (CSF), 1-methyl4-phenyl-1,2,3,6-tetrahydropyridine (MPTP), 1-methyl-4phenylpyridinium (MPP+), dopaminergic (DA), Amyotrophic lateral sclerosis/Parkinsonian dementia complex (ALS/PDC)

Magnesium levels are lower than normal in brains of PD patients and animal models of PD

Several studies have used spectroscopic methods to measure magnesium levels in postmortem brain tissue from PD patients, or in serum and CSF of living patients (Table 1). In one, using inductively coupled plasma atomic emission spectrometry, magnesium levels were found to be lower in the cortex, white matter, basal ganglia, and brainstem of PD brains in comparison to control brains ${ }^{1}$. In another, phosphorus magnetic resonance spectroscopy showed that average cytosolic free magnesium was lower in the occipital lobes of 13 PD patients than in those of 16 healthy age-matched controls ${ }^{2}$. 


\begin{tabular}{|c|c|c|c|c|}
\hline Sample Size & Sample Type & $\mathrm{Mg}^{2+}$ Levels & ${ }^{*}$ Free or Total $\mathbf{M g}^{2+}$ & Citation \\
\hline $\begin{array}{l}4 \text { PD } \\
5 \text { control }\end{array}$ & $\begin{array}{l}\text { Brain tissue } \\
\text { ( } 26 \text { regions) }\end{array}$ & Reduced by an average of $191.6 \mu \mathrm{g} / \mathrm{g}$ in all regions (PD vs control) & Total & 1 \\
\hline $\begin{array}{l}13 \text { PD } \\
16 \text { control }\end{array}$ & $\begin{array}{l}\text { Brain tissue } \\
\text { (occipital lobe) }\end{array}$ & $\begin{array}{l}143 \pm 11 \mathrm{mM} \text { (PD) } \\
\text { vs } 181 \pm 23 \mathrm{mM} \text { (control) }\end{array}$ & Free & 2 \\
\hline $\begin{array}{l}9 \text { PD } \\
12 \text { control }\end{array}$ & $\begin{array}{l}\text { Brain tissue } \\
\text { (caudate nucleus) }\end{array}$ & $\begin{array}{l}471 \pm 28 \mu \mathrm{g} / \mathrm{g} \text { (PD) } \\
\text { vs } 530 \pm 11 \mu \mathrm{g} / \mathrm{g} \text { (control) }\end{array}$ & Total & 3 \\
\hline $\begin{array}{l}91 \text { PD } \\
18 \text { control }\end{array}$ & CSF & $\begin{array}{l}\text { Diagnosed }<1 \text { year }=26.9 \pm 3.0 \mu \mathrm{g} / \mathrm{mL} \\
\text { Diagnosed }>8 \text { years }=20.9 \pm 1.7 \mu \mathrm{g} / \mathrm{mL}\end{array}$ & Total & 4 \\
\hline $\begin{array}{l}91 \text { PD } \\
18 \text { control }\end{array}$ & Blood & $31.7 \pm 4.7 \mu \mathrm{g} / \mathrm{mL}$ (PD) vs $26.5 \pm 4.8 \mu \mathrm{g} / \mathrm{mL}$ (control) & Total & 4 \\
\hline $\begin{array}{l}20 \text { PD } \\
15 \text { control }\end{array}$ & CSF & $\begin{array}{l}31.6 \pm 3.6 \mu \mathrm{g} / \mathrm{mL} \text { (PD) } \\
\text { vs } 29.6 \pm 6.5 \mu \mathrm{g} / \mathrm{mL} \text { (control) - No significant difference }\end{array}$ & Total & 5 \\
\hline $\begin{array}{l}13 \text { PD } \\
4 \text { control }\end{array}$ & $\begin{array}{l}\text { Brain tissue } \\
\text { (substantia nigra) }\end{array}$ & No significant difference (exact values not reported) & Total & 6 \\
\hline
\end{tabular}

Table 1: *The measurement of free or total $\mathrm{Mg}^{2+}$ was deduced by the technology used and was not explicitly stated by the authors

Atomic absorption and atomic emission spectroscopy was applied to four brain regions from 9 PD patients and 12 controls; lower concentrations of magnesium were present specifically in the caudate nucleus of Parkinsonian brains $^{3}$. A further study found that magnesium levels in the CSF correlated inversely with duration and severity of PD, whereas levels of magnesium in the blood of PD patients were slightly higher than normal ${ }^{4}$. The authors noted that blood magnesium levels may be more sensitive to short term variation affected by diet than the levels in the CSF. However, in two other studies of similar scale magnesium levels were not significantly lower in the $\mathrm{CSF}^{5}$ or brain tissue $^{6}$ of PD patients versus controls, consistent with variable pathogenic mechanisms among cases of PD .

Deficiencies of dietary magnesium have also been noted in patients with PD. A case-control study in Japan found that higher iron, magnesium, and zinc intake was associated with reduced risk of PD and that the inverse association remained after adjustment for intake of other elements $^{7}$. Another found that lower intake of protein, folate, magnesium, and phosphorus was associated with lower olfactory acuity - an early symptom of both PD and Alzheimer's - in both PD patients and controls ${ }^{8}$. Amyotrophic lateral sclerosis/Parkinsonian dementia complex (ALS/PDC), observed at high incidence among the Chamorro population on Guam especially in the 1950s, has been attributed to nutritional deficiencies in calcium and magnesium 9 . In the Kii Peninsula of Japan, as on Guam, an increased risk for ALS/PDC was associated with significantly lower levels of manganese in food and magnesium in drinking water ${ }^{10}$. Moreover, declining incidence of the disease in Guam coincided with a shift towards a more Western diet richer in magnesium and calcium ${ }^{11}$. However, despite the correlation of low dietary magnesium and risk for ALS/PDC, a study in 1995 did not detect significantly different levels of free magnesium in urine and blood of 12 ALS/PDC patients and 12 Chamorro controls ${ }^{12}$. We conclude that the etiology of most Parkinsonian disorders is complex, and nutritional deficiency may contribute to it in some cases.

Several animal- and cell-based experiments support a neuroprotective effect of magnesium. Rats treated with 6-hydroxydopamine (a common PD animal model) had lower levels of magnesium and other elements compared to control $^{13}$. Rats that were fed a low magnesium diet continuously for one year (including during the prenatal period) displayed a marked reduction in both levels of serum magnesium and numbers of dopaminergic neurons of the substantia nigra at one year of age $\mathrm{e}^{14}$. In another study, mice fed a low magnesium diet for six weeks developed catalepsy and had a reduction in the amount of tyrosine hydroxylase-positive neurons in the substantia nigra compared to controls ${ }^{15}$.

Thelinkbetween reduced magnesium levelsandelevated risk for PD may be oxidative stress, a long-suspected culprit PD-related neurodegeneration (recently reviewed ${ }^{16}$ ). Low magnesium levels have been linked to oxidative stress in traumatic brain injury ${ }^{17}$. Magnesium supplementation in a canine model of cardiac infarction lowered ascorbate free radical levels ${ }^{18}$. The dopaminergic toxin MPTP specifically inhibits complex I of the electron transfer chain and greatly increases the production of free radicals ${ }^{19}$. Work from the Oka group showed that a reduction in magnesium levels elevates ROS and sensitizes PC12 cells to MPTP ${ }^{20}$, and that overexpression of the magnesium transporter SLC41A2 can protect against MPTP-induced death ${ }^{21}$. In summary, results from epidemiology, animal studies, and cell lines all implicate magnesium as a contributing factor in at least some forms of Parkinsonism.

Mutations in genes encoding proteins involved in magnesium homeostasis

Given the evidence connecting lower-than-normal magnesium levels to elevated risk for PD, it might be expected that mutations in genes encoding regulators of magnesium homeostasis would predispose individuals 
to PD. The levels of intracellular and extracellular free magnesium are nearly identical (roughly 0.5-1.2 $\mathrm{mM})^{22}$, although levels of total cytoplasmic magnesium are considerably higher than those of free magnesium (around $5 \mathrm{mM}$ ), with the majority complexed with ATP ${ }^{22}$. Although numerous ion channels and transporters have been implicated in control of magnesium homeostasis in eukaryotic cells, including TRPM7, MAGT1, CNNM2, SLC41 paralogs, ACDP paralogs, NIPA paralogs, and HIP14 paralogs ${ }^{23}$, to our knowledge, only two are implicated in inherited risk for any parkinsonian disorder, i.e., SLC41A1 and TRPM7.

\section{SLC41A1}

The PARK16 locus was initially identified in a pair of GWAS of PD disease patients of European and Japanese descent $^{24,25}$. This locus harbors 6 genes, three of which NUCKS1, SLC41A1, and RAB7L1 - are considered candidates for the causative gene. SLC41A1 encodes a protein distantly related to the bacterial MgtE magnesium transporters ${ }^{26}$. Because of the connections between magnesium homeostasis and PD risk, SLC41A1 is good candidate for the causative gene. Supporting SLC41A1 as the causative gene, a SNP within SLC41A1 (rs11230569) was associated with a lower risk of PD in independent studies of Iranian and Chinese cohorts $^{27,28}$. Interestingly, although this SNP is synonymous, the GTex study of expression quantitative trait loci (eQTL) shows that it is associated with altered expression of SLC41A1 (but not of RAB7L1 or NUCKS1) in several tissues $^{29}$. The SLC41A1 coding variant p.A350V was identified in one of a cohort of 454 PD cases, but absent in 483 controls $^{30}$. It is also missing among 60,706 individuals in the ExAc database, strengthening the case that SLC41A1 is the causative gene in the PARK16 locus ${ }^{31}$. Patch clamp recordings of HEK293 cells forced to express SLC41A1 A350V indicated that this variant is over-active, resulting in a reduction of cellular magnesium levels ${ }^{32}$. In a separate study, a variant in SLC41A1 (R244H) was identified in one case of early onset PD, but not in $479 \mathrm{PD}$ patients with age of onset over 50 or in 525 normal controls ${ }^{33}$ (a frequency of less than 1 in 10,000 alleles currently represented in the ExAc study ${ }^{31}$ ). When this variant was cloned and expressed in HEK293-derived cells, it was still able to correctly localize to the plasma membrane but was less effective at magnesium efflux than the wildtype protein ${ }^{33}$. A final study found one noncoding and two coding variants in SLC41A1, but not in $R A B 7 L 1$, that were found amongst $205 \mathrm{PD}$ patients yet not in 210 controls $^{34}$.

Nonetheless, it is by no means certain that SLC41A1 is the causative gene in PARK16. For instance, RAB7L1 encodes a protein that can bind and alter the activity of the strongly-PD associated LRKK2 protein $^{35}$. Moreover, the GTex study found that, in contrast to some other SNPs in PARK17, rs947211 (associated with PD in GWAS of both
European and Asian populations ${ }^{36}$ ) is an eQTL for RAB7L1 and NUCKS1 in many tissues, and for SLC41A1 in just one $^{29}$. It has been discussed that there may be more than one pathogenic gene in this locus ${ }^{30}$. Animal model studies of SLC41A1 function in vivo - for instance in mouse or zebrafish mutants or in cell line models of dopaminergic neurons - would help to assess the likelihood that SLC41A1 is indeed a causative gene for PD.

\section{TRPM7}

Transient receptor potential melastatin-like 7 (TRPM7) encodes an ion channel with a C-terminal kinase domain. The channel is permeable to magnesium, calcium, zinc, and other trace metals. Channel activity is inhibited by intracellular magnesium, and is stimulated by PIP2 and perhaps by stretch (reviewed in ${ }^{37}$ ). Early studies in tissue culture showed that TRPM7 is essential for cell proliferation and viability ${ }^{38,39}$. Cells depleted of TRPM7 had lower-than-normal levels of intracellular magnesium, and supplementation of the culture media with magnesium rescued cell growth and viability ${ }^{38}$, indicating that TRPM7 regulates cellular magnesium homeostasis. Later loss-offunction studies, through targeted mutation or morpholinomediated knockdown, reveal that TRPM7 is essential for morphogenesis of mice and frogs ${ }^{40,41}$. Overexpression of SLC41A2, a magnesium transporter closely related to SLC41A1 discussed above, rescued morphogenesis in frog embryos depleted of TRPM7, indicating that the essential function of TRPM7 during morphogenesis is also regulation of cellular magnesium homeostasis ${ }^{41}$. Tissue specific knockout in mice reveals that TRPM7 is also necessary for differentiation of thymocytes ${ }^{40}$, sensory neurons, melanocytes, and potentially other cell types ${ }^{42}$. Interestingly, cellular magnesium homeostasis was not grossly perturbed in thymocytes or T-lymphocytes lacking $\mathrm{TRPM}^{40}$. Because TRPM7 is permeable to ions other than magnesium, and because it has a kinase domain that can be cleaved and migrate to the nucleus ${ }^{43}$ the role of TRPM7 in some developmental or physiological contexts may be independent of its function as a magnesium channel. For instance, studies in cultured neurons and rats indicate that excessive flow of calcium and possibly zinc through TRPM7 is toxic to neurons ${ }^{44,45}$. In summary, TRPM7 is a combined channel and kinase that is necessary for cell migration, proliferation, survival, and differentiation, but which also mediates a toxic influx of divalent cations in certain physiologic conditions.

A missense variant of TRPM7, T1482I, was reported to be present in 5 of 22 Guamanian ALS/PDC patients and absent from 23 age-matched controls from the same ethnic group, i.e., the indigenous Chamorros ${ }^{46}$. The TRPM7 T1482I variant was shown to have a lower peak current and to be more sensitive to inhibition by intracellular magnesium than the reference variant ${ }^{46}$. However, a separate study on 
a similar scale (25 patients and 27 age-matched regional controls) in the Kii peninsula, where this disease is also prevalent, detected no association between the disease and the mutation causing the T1482I variant ${ }^{47}$. Moreover, in the ExAc study, this variant represented $8.7 \%$ of TRPM7 alleles sequenced, and many homozygotes were detected ${ }^{31}$. Importantly, the frequency of the T1482I variant among the Chamorros and among individuals in the Kii peninsula is unknown. Nonetheless, the genetic evidence that this predisposes people to Parkinsonian conditions, except perhaps in conditions of low dietary magnesium, is weak.

In this context it is interesting that the phenotype of zebrafish trpm 7 loss-of-function mutants, identified in several chemical mutagenesis screens, support a role for TRPM7 in the differentiation, and possibly survival, of dopaminergic neurons. Unlike mouse and Xenopus embryos deficient in TRPM7, zebrafish trpm7 mutants undergo early morphogenesis normally ${ }^{48,49}$. However, at 5 days post fertilization, loss-of-function mutants exhibit significantly less spontaneous swimming than their wildtype and heterozygous siblings ${ }^{50}$. Motility is elevated by application of L-DOPA (a dopamine precursor), implicating a dysfunctional DA system ${ }^{50}$. Indeed, histology revealed that whereas the number of precursors expressing Dopamine transporter (dat) is normal in trpm 7 mutants, only about half of the normal number of TH-positive neurons are present in mutants ${ }^{50}$. These results indicate that in zebrafish Trpm7 is necessary for terminal differentiation of at least a subset of dopaminergic neurons. In addition, residual TH-positive neurons in trpm 7 mutant zebrafish larvae are hypersensitive to the toxic effects of MPTP and MPP $+{ }^{50}$, consistent with the possibility that Trpm7 is necessary for the maintenance of dopaminergic neurons, not just their differentiation. Supporting this possibility, overexpression of a channel dead variant of TRPM7 in SHSY5Y cells - which are dopaminergic - blocks proliferation and survival ${ }^{50}$.

\section{Outstanding questions for future research}

Ever increasing sample sizes and sequencing depth of PD patients and controls - including whole genome sequences - will yield increasing power and resolution of genetic studies, strengthening or weakening the case for SLC41A1, TRPM7, and potentially other magnesium transporters and channels as causative genes for PD. Meanwhile, efforts to illuminate the roles of SLC41A1 and TRPM7 in the development, function, and maintenance of dopaminergic neurons will benefit from studies in cell lines and in animal models, including zebrafish. Cell lines are more tractable than in vivo models for physiology and some pharmacology experiments. However, animal models offer the ability to study dopaminergic neurons in their normal context; for studies of Trpm7 in vivo, the zebrafish mutant is particularly useful as the mouse mutant is embryonic lethal. Future studies in animal models may answer questions including: Why are dopaminergic neurons compromised to a greater degree than other cell types by a given variant of SLC41A1 or TRPM7? Do both loss and gainof-function variants of SLC41A1 disrupt the dopaminergic system, as indicated by human genetic studies? What is the connection between TRPM7 function, magnesium homeostasis, and the physiology and development of dopamine neurons? In this context, does TRPM7's kinase domain contribute, beyond modulating the sensitivity of the channel to inhibition by internal magnesium ${ }^{37}$ ? TRPM7 may contribute to maintaining ion homeostasis in intracellular vesicles, including synaptic vesicles ${ }^{51}$, and defects in vesicle trafficking are proposed to play a major role in $\mathrm{PD}^{52}$. Another possibility is that, by maintaining correct magnesium levels, Trpm7 protects against buildup of ROS, particularly in the context of the oxidative chemistry of dopamine synthesis ${ }^{20}$. And finally, in which cell type is SLC41A1 (or TRPM7) required to maintain healthy dopaminergic neurons?

\section{Conclusion}

To date there is little evidence that sequence variants near genes encoding magnesium transporters contribute a large portion of heritable risk for idiopathic PD, although they may contribute a measure of such risk. By contrast the evidence that magnesium homeostasis is relevant to the survival and function of dopaminergic neurons is relatively strong. Therefore, regulatory pathways governing magnesium homeostasis are worth investigating as therapeutic targets for PD.

\section{Acknowledgements}

We are grateful to Kumar Narayanan for thoughtful comments on this minireview. Research in the Cornell lab on dopamine neurons is supported by a grant from the National Institute of Neurological Disease and Stroke (NS09859,PI: Alex Bassuk).

\section{References}

1. Yasui M, Kihira T, Ota K. Calcium magnesium and aluminum concentrations in Parkinson's disease. Neurotoxicology. 1992; 13(3): 593-600.

2. Barbiroli B, Martinelli P, Patuelli A. Phosphorus magnetic resonance spectroscopy in multiple system atrophy and Parkinson's disease. Mov Disord. 1999; 14(3): 430-435.

3. Uitti RJ, Rajput AH, Rozdilsky B. Regional metal concentrations in Parkinson's disease other chronic neurological diseases and control brains. Canadian Journal of Neurological Sciences/Journal Canadien des Sciences Neurologiques. 1989; 16(03): 310-314.

4. Bocca B, Alimonti A, Senofonte O. Metal changes in CSF and peripheral compartments of parkinsonian patients. Journal of the neurological sciences. 2006; 248(1): 23-30.

5. Hozumi I, Hasegawa T, Honda A. Patterns of levels of biological metals in CSF differ among neurodegenerative diseases. Journal of the neurological sciences. 2011; 303(1): 95-99.

6. Riederer P, Sofic E, Rausch WD. Transition metals ferritin glutathione 
and ascorbic acid in parkinsonian brains. Journal of neurochemistry. 1989; 52(2): 515-520.

7. Miyake Y, Tanaka K, Fukushima W. Dietary intake of metals and risk of Parkinson's disease A case control study in Japan. Journal of the Neurological Sciences. 2011; 306(1-2): 98-102, doi:http://dx.doi. org/10.1016/j.jns.2011.03.035.

8. Ådén E, Carlsson M, Poortvliet E. Dietary intake and olfactory function in patients with newly diagnosed Parkinson's disease a case control study. Nutritional neuroscience. 2011; 14(1): 25-31.

9. Oyanagi $\mathrm{K}$. The nature of the parkinsonism-dementia complex and amyotrophic lateral sclerosis of Guam and magnesium deficiency. Parkinsonism \& Related Disorders. 2005; 11, Supplement 1 S17-S23, doi:http://dx.doi.org/10.1016/j.parkreldis.2005.02.010.

10. Iwami O, Watanabe T, Moon CS, et al. Motor neuron disease on the Kii Peninsula of Japan: excess manganese intake from food coupled with low magnesium in drinking water as a risk factor. Science of The Total Environment. 1994; 149(1): 121-135, doi:http://dx.doi. org/10.1016/0048-9697(94)90010-8.

11. Garruto RM, Yanagihara R, Gajdusek DC. Disappearance of highincidence amyotrophic lateral sclerosis and parkinsonism-dementia on Guam. Neurology. 1985; 35(2): 193-193.

12. Ahlskog JE, Waring SC, Kurland LT. Guamanian neurodegenerative disease investigation of the calcium metabolism heavy metal hypothesis. Neurology. 1995; 45(7): 1340-1344.

13. Xu R, Zhou Y, Fang X. The possible mechanism of Parkinson's disease progressive damage and the preventive effect of GM1 in the rat model induced by 6-hydroxydopamine. Brain Research. 2014; 1592: 73-81. doi:http://dx.doi.org/10.1016/j.brainres.2014.09.053.

14. Oyanagi K, Kawakami E, Kikuchi-Horie K. Magnesium deficiency over generations in rats with special references to the pathogenesis of the parkinsonism dementia complex and amyotrophic lateral sclerosis of Guam. Neuropathology. 2006; 26(2): 115-128.

15. Taniguchi $R$, Nakagawasai 0 , Tan-no K. Combined low calcium and lack magnesium is a risk factor for motor deficit in mice. Bioscience biotechnology and biochemistry. 2013; 77(2): 266-270.

16. Blesa J, Trigo Damas I, Quiroga Varela A, et al. Oxidative stress and Parkinson's disease. Frontiers in Neuroanatomy. 2015; 9: 91. doi:10.3389/fnana.2015.00091.

17. CERNAK I, Savic VJ, Kotur J. Characterization of plasma magnesium concentration and oxidative stress following graded traumatic brain injury in humans. Journal of neurotrauma. 2000; 17(1): 53-68.

18. Garcia LA, Dejong SC, Martin SM. Magnesium reduces free radicals in an in vivo coronary occlusion-reperfusion model. Journal of the American College of Cardiology. 1998; 32(2): 536-539. doi:10.1016/ S0735-1097(98)00231-9.

19. Cleeter MWJ, Cooper JM, Schapira AHV. Irreversible Inhibition of Mitochondrial Complex I by 1-Methyl-4-Phenylpyridinium: Evidence for Free Radical Involvement. Journal of Neurochemistry. 1992; 58(2): 786-789, doi:10.1111/j.1471-4159.1992.tb09789.x.

20. Shindo Y, Yamanaka R, Suzuki K, et al. Intracellular magnesium level determines cell viability in the MPP+ model of Parkinson's disease. Biochimica et Biophysica Acta (BBA)-Molecular Cell Research. 2015; 1853(12): 3182-3191

21. Shindo Y, Yamanaka R, Suzuki K, et al. Altered expression of Mg2 + transport proteins during Parkinson's disease-like dopaminergic cell degeneration in PC12 cells. Biochimica et Biophysica Acta (BBA) - Molecular Cell Research. 2016; 1863(8): 1979-1984. doi:http:// dx.doi.org/10.1016/j.bbamcr.2016.05.003.

22. Romani AMP. Cellular magnesium homeostasis. Archives of Biochemistry and Biophysics. 2011; 512(1): 1-23. doi:http://dx.doi. org/10.1016/j.abb.2011.05.010.
23. de Baaij JHF, Hoenderop JGJ, Bindels RJM. Magnesium in Man: Implications for Health and Disease. Physiological Reviews. 2015; 95(1): 1-46. doi:10.1152/physrev.00012.2014.

24. Simon Sanchez J, Schulte C, Bras JM. Genome wide association study reveals genetic risk underlying Parkinson's disease. Nature genetics. 2009; 41(12): 1308-1312.

25. Satake W, Nakabayashi Y, Mizuta I. Genome wide association study identifies common variants at four loci as genetic risk factors for Parkinson's disease. Nat Genet. 2009; 41(12): 1303-1307. doi:http:// www.nature.com/ng/journal/v41/n12/suppinfo/ng.485_S1.html.

26. Fleig A, Schweigel Röntgen M, Kolisek, M. Solute carrier family SLC41 what do we really know about it? Wiley Interdisciplinary Reviews Membrane. Transport and Signaling. 2013; 2(6): 227-239. doi:10.1002/wmts.95.

27. Madadi F, Khaniani MS, Shandiz EE. Genetic Analysis of the ZNF512B SLC41A1 and ALDH2 Polymorphisms in Parkinson's Disease in the Iranian Population. Genetic Testing and Molecular Biomarkers. 2016; 20(10): 629-632.

28. Wang L, Cheng L, Li NN. Genetic analysis of SLC41A1 in Chinese Parkinson's disease patients. American journal of medical genetics Part B Neuropsychiatric genetics the official publication of the International Society of Psychiatric Genetics. 2015; 168(8): 706-711. doi:10.1002/ajmg.b.32365.

29. Consortium G. The Genotype-Tissue Expression (GTEx) pilot analysis: Multitissue gene regulation in humans. Science. 2015; 348(6235): 648-660.

30. Tucci A, Nalls MA, Houlden H. Genetic variability at the PARK16 locus. Eur J Hum Genet. 2010; 18(12): 1356-1359. doi:http://www.nature. com/ejhg/journal/v18/n12/suppinfo/ejhg2010125s1.html.

31. Lek M, Karczewski KJ, Minikel EV. Analysis of protein-coding genetic variation in 60,706 humans. BioRxiv. 2016; 030338.

32. Kolisek M, Sponder G, Mastrototaro L. Substitution p.A350V in $\mathrm{Na}+/$ Mg2+ Exchanger SLC41A1, Potentially Associated with Parkinson's Disease Is a Gain-of-Function Mutation. PLoS ONE. 2013; 8(8): e71096. doi:10.1371/journal.pone.0071096.

33. Lin $\mathrm{CH}, \mathrm{Wu}$ YR, Chen WL. Variant $\mathrm{R} 244 \mathrm{H}$ in $\mathrm{Na}+\mathrm{Mg} 2+$ exchanger SLC41A1 in Taiwanese Parkinson's disease is associated with loss of Mg 2+ efflux function. Parkinsonism \& related disorders. 2014; 20(6): 600-603.

34. Yan Y, Tian J, Mo X. Genetic variants in the RAB7L1 and SLC41A1 genes of the PARK16 locus in Chinese Parkinson's disease patients. International Journal of Neuroscience. 2011; 121(11): 632-636.

35. MacLeod DA, Rhinn H, Kuwahara T. RAB7L1 interacts with LRRK2 to modify intraneuronal protein sorting and Parkinson's disease risk. Neuron. 2013; 77(3): 425-439.

36. Li H, Teo YY, Tan EK. Patterns of linkage disequilibrium at PARK16 may explain variances in genetic association studies. Mov Disord. 2015; 30(10): 1335-1342. doi:10.1002/mds.26176.

37. Penner R, Fleig A. in Transient Receptor Potential (TRP) Channels. springer.2007; 313-328.

38. Schmitz C, et al. Regulation of vertebrate cellular Mg 2+ homeostasis by TRPM7. Cell. 2003; 114(2): 191-200.

39. Nadler MJ, et al. LTRPC7 is a Mg• ATP regulated divalent cation channel required for cell viability. Nature. 2001; 411(6837): 590-595.

40. Jin J, Desai BN, Navarro B. Deletion of Trpm7 Disrupts Embryonic Development and Thymopoiesis Without Altering $\operatorname{Mg}(2+)$ Homeostasis. Science New York NY. 2008; 322(5902): 756-760. doi:10.1126/science.1163493.

41. Liu W, Su LT, Khadka DK. TRPM7 regulates gastrulation during vertebrate embryogenesis. Developmental biology. 2011; 350(2): 348-357. 
42. Jin J, Wu LJ, Jun J. The channel kinase TRPM7 is required for early embryonic development. Proceedings of the National Academy of Sciences. 2012; 109(5): E225-E233. doi:10.1073/pnas.1120033109.

43. Krapivinsky G, Krapivinsky L, Manasian Y, et al. The TRPM7 Chanzyme Is Cleaved to Release a Chromatin-Modifying Kinase. Cell. 2014; 157(5): 1061-1072. doi:http://dx.doi.org/10.1016/j. cell.2014.03.046.

44. Aarts M, Iihara K, Wei WL. A Key Role for TRPM7 Channels in Anoxic Neuronal Death. Cell. 2003; 115(7): 863-877. doi:http://dx.doi. org/10.1016/S0092-8674(03)01017-1.

45. Kim, Y. et al. Stress hormone potentiates Zn2+-induced neurotoxicity via TRPM7 channel in dopaminergic neuron. Biochemical and Biophysical Research Communications. 2016; 470(2): 362-367, doi:http://dx.doi.org/10.1016/j.bbrc.2016.01.041.

46. Hermosura MC, Nayakanti H, Dorovkov MV. A TRPM7 variant shows altered sensitivity to magnesium that may contribute to the pathogenesis of two Guamanian neurodegenerative disorders. Proceedings of the National Academy of Sciences of the United States of America. 2005; 102(32): 11510-11515. doi:10.1073/ pnas. 0505149102 .

47. Hara K, Kokubo Y, Ishiura H. TRPM7 is not associated with amyotrophic lateral sclerosis-parkinsonism dementia complex in the Kii peninsula of Japan. American Journal of Medical Genetics Part B
Neuropsychiatric Genetics. 2010; 153B(1): 310-313. doi:10.1002/ ajmg.b.30966.

48. Elizondo MR, Arduini BL, Paulsen J. Defective Skeletogenesis with Kidney Stone Formation in Dwarf Zebrafish Mutant for trpm7. Current Biology. 2005; 15(7): 667-671. doi:http://dx.doi.org/10.1016/j. cub.2005.02.050.

49. Cornell RA, Yemm E, Bonde G. Touchtone promotes survival of embryonic melanophores in zebrafish. Mechanisms of Development. 2004; 121(11): 1365-1376. doi:http://dx.doi.org/10.1016/j. $\bmod 2004.06 .005$.

50. Decker AR, McNeill MS, Lambert AM. Abnormal differentiation of dopaminergic neurons in zebrafish trpm7 mutant larvae impairs development of the motor pattern. Developmental biology. 2014; 386(2): 428-439.

51. Krapivinsky G, Mochida S, Krapivinsky L, et al. The TRPM7 ion channel functions in cholinergic synaptic vesicles and affects transmitter release. Neuron. 2006; 52(3): 485-496. doi:10.1016/j. neuron.2006.09.033.

52. Kalinderi K, Bostantjopoulou S, Fidani L. The genetic background of Parkinson's disease: current progress and future prospects. Acta Neurologica Scandinavica. 2016; 134(5): 314-326, doi:10.1111/ ane.12563. 